\title{
Botulinum Toxin as a Stand-Alone Treatment for Muscle Spasticity: Review of the Evidence
}

\section{Abdel Magid O Bakheit*}

Emeritus Professor of Neurological Rehabilitation, Moseley Hall hospital, United Kingdom

\begin{abstract}
Botulinum toxin has been shown to reduce muscle tone and improve motor function in children and adults with muscle spasticity. However, it is not clear whether the magnitude and/ or the duration of the beneficial effect of this treatment are increased by combining it with other spasticity treatments. Nonetheless, some guidelines on the management of spasticity recommend that botulinum toxin is not used unless it is combined with other spasticity treatment modalities, such as physiotherapy. In this article it is argued that the clinical evidence that supports such recommendations is at best weak and that the recommendations are probably too restrictive. It is further suggested that the use of botulinum toxin as a stand-alone treatment of spasticity is justifiable, especially when other therapies are not immediately available for use in combination with the toxin.
\end{abstract}

Keywords: Botulinum toxin; muscle spasticity; Motor function

\section{Introduction}

Several randomised controlled trials [1-4] have shown that botulinum toxin (BoNT) type A and type B reduce muscle tone as measured with the modified Ashworth scale, reduce the frequency of muscle spasms and pain, increase the joints range of motion and improve motor function in patients with muscle spasticity. The duration of benefit is usually 16 weeks and the beneficial effect is often maintained with repeated treatment cycles [5]. However, preliminary evidence from animal experiments suggests that the treatment effect may be enhanced by combining BoNT with other spasticity treatments but there is insufficient clinical evidence for this. Nonetheless, some guidelines on the management of spasticity recommend that botulinum toxin is used only as an adjunct to other treatment modalities, such as physiotherapy.

The British national guidelines for the management of muscle spasticity [6] acknowledge the value of botulinum toxin (BoNT) in the management of this disorder. However, the guidelines recommend that BoNT is used only as an adjunct to other therapeutic modalities. Similarly, a European consensus statement [7] endorses the use of BoNT in the management of focal and multi focal spasticity but concludes that "before using botulinum toxin type A the team must ensure that an appropriate rehabilitation management programme is in place and available post-injection". Although the recommended rehabilitation programme is not spelled out in this document, it is implicit that some form of therapy intervention is considered a requisite for the use of BoNT. These recommendations appear to be at odds with the current practice of a significant number of clinicians.

Evidence from routine clinical practice worldwide suggests that BoNT is frequently used successfully as the sole treatment of spasticity. For example, a recent international survey of the use of BoNT in 122 treatment centres across 31 countries in Europe, the Middle East, Asia and South America [8] has shown that only $70.6 \%$ of patients who were treated with BoNT for upper limb spasticity received physiotherapy, $34.4 \%$ were prescribed an orthosis and just 9.1\% had functional electrical stimulation.

The reasons for the discrepancy between the recommendations in the above-mentioned guidelines and current clinical practice are not clear. Nonetheless, it is important to examine the evidence for the possible advantages of combining BoNT with other antispasticity interventions such as physiotherapy. This, if proven, should encourage better compliance with the afore-mentioned guidelines. Alternatively, if such evidence is weak or lacking, it would be important to review the recommendations so that treatment with BoNT is not denied or delayed due to the unavailability of other therapy services or delays in accessing them.

\section{The Experimental Support for Combining Botulinum Toxin with other Antispasticity Treatments}

The degree of muscle denervation caused by BoNT has been shown to be proportional to the extent of the toxin's binding to the neuromuscular junction $[9,10]$. The muscle denervation (and the clinical effect of BoNT) is not permanent and it wears off when neurotransmission is restored by axonal sprouting [11]. Consequently, it is plausible that measures that enhance the toxin uptake at the motor endplate or interfere with axonal sprouting are likely to increase the magnitude and/or the duration of the clinical effect of BoNT. Interestingly, in some cases reduced sprouting of the muscle that is denervated with BoNT appears to be increased by muscle exercise and electrical stimulation [12].

Exercise after partial muscle denervation either enhances or reduces neuronal sprouting depending on the extent of denervation. For example, Gardiner et al. [13] have found that exercise training enhanced sprouting in the plantaris, and reduced sprouting in the soleus muscle of the partially denervated hind limbs of rats. Electrical stimulation (ES) has a similar effect. In a study of rats with partially denervated hind limb muscles increased physical activity or the use of ES suppressed terminal axonal sprouting after extensive (>80\%) denervation but not after moderate ( 50\%) denervation [14].

*Corresponding author: Abdel Magid O Bakheit, MD, PhD, FRCP, Emeritus Professor of Neurological Rehabilitation, Moseley Hall hospital, Alcester Road Birmingham B13 8JL, United Kingdom, Tel: +44121-4666595; Fax: +441214423694; E-mail: magid.bakheit@bhamcommunity.nhs.uk

Received February 15, 2013; Accepted April 08, 2013; Published April 11, 2013

Citation: Bakheit AMO (2013) Botulinum Toxin as a Stand-Alone Treatment for Muscle Spasticity: Review of the Evidence. J Neurol Disord 1: 109. doi:10.4172/ 2329-6895.1000109

Copyright: ( 2013 Bakheit AMO. This is an open-access article distributed under the terms of the Creative Commons Attribution License, which permits unrestricted use, distribution, and reproduction in any medium, provided the original author and source are credited. 
Suppression of axonal sprouting appears to be responsible for the increased paralytic clinical effect of BoNT following muscle exercise or electrical stimulation. In one study repeated stretching of the rabbit muscle after BoNT injections resulted in more muscle paralysis and this effect also lasted longer than when BoNT was used alone [15]. Similarly, when electrical stimulation was given after BoNT injections into isolated frog phrenic nerve-diaphragm preparation the paralytic effect and the speed with which the paralysis occurred increased. Interestingly, the magnitude of this effect was proportional to the rate of stimulation [16].

Although experimental studies suggest that muscle stretching and electrical stimulation may augment the paralytic effect of BoNT, the evidence from clinical practice is either weak or contradictory.

\section{The Evidence for the Enhanced Clinical Effect of BoNT Combination Therapy}

Few randomised controlled trials compared the duration or magnitude of muscle tone reduction when BoNT was used as the sole treatment of spasticity with that when it was combined with other spasticity treatment methods including physical therapy and muscle or nerve electrical stimulation. The inadequate design and small number of these studies does not allow meta-analysis of the data generated by these trials. These studies are reviewed in the following sections and summarised in the table.

\section{Botulinum toxin and physiotherapy}

The clinical studies that attempted to establish whether the combined administration of physiotherapy with BoNT enhances the beneficial effect of the toxin are few and inconclusive. The numbers of patients studied are small and the design of the studies is generally inadequate.

The most recent study of combination therapy [17] compared the effect of two types of physical therapy (physical training with or without progressive resistance training) in the treatment of ankle plantar flexor spasticity in 14 children with spastic cerebral palsy. Physiotherapy was given for 12 weeks. Both study groups also received one cycle of treatment with BoNT. Although there was a similar reduction in the antagonist muscle activity following both forms of physiotherapy, no change in motor function was observed in either group at the end of the study. The design of this study does not allow any conclusions to be drawn on whether BoNT combination with either of the two forms of physiotherapy is superior to treatment with BoNT alone.

In another study [18], 38 patients with secondary progressive multiple sclerosis were randomised to receive BoNT injections alone or in combination with a physiotherapy programme consisting of 40 minutes of muscle stretching for 15 consecutive days. Assessment of muscle tone was made with the Modified Ashworth scale and the Visual Analogue scale at baseline and at the end of weeks 2, 4 and 12. The authors reported a statistically significant difference between the groups in favour of the combined BoNT and physiotherapy group. However, the subjective nature of the outcome measures used and the small sample size diminish the value of this study.

The addition of BoNT to physiotherapy has also resulted in clinical effects similar to those of physiotherapy alone in children with spastic cerebral palsy. Chaturvedi et al. [19] compared BoNT and physiotherapy with physiotherapy alone in 36 children with diplegic cerebral palsy. The study outcome measures were quantitative tensor tractography of the motor and sensory muscle fibre bundles and clinical motor function as measured with the Gross Motor Function Measure. At 6 months there was no significant difference between the two groups in any of the outcome measures used. This suggests that as in adults, to date there has been no conclusive evidence for the value BoNT-physiotherapy combination in children with spasticity. Research studies in this area have so far been sparse and of poor quality and further evidence from ongoing well-designed randomised controlled trials with the appropriate sample size [20] is eagerly anticipated.

\section{Botulinum toxin and electrical stimulation}

A number of studies investigated the effect of combining electrical stimulation (ES) with BoNT. Of these two studies by the same group of investigators reported that ES augmented the effect of BoNT injections in patients with muscle spasticity $[21,22]$. The first study was an open label trial of 10 patients. The second was a small randomised controlled trial. Patients with upper limb muscle spasticity were randomly allocated to one of four groups. The patients received either BoNT-A alone, placebo alone, BoNT-A plus ES, or placebo plus ES. Each group consisted of six patients. ES was given for 30 minutes three times a day for three days after the injections. Statistically significant reduction in muscle tone (as measured with the modified Ashworth scale and ease of care) was observed in the BoNT-A plus ES and the placebo plus ES groups compared to the other groups.

In another investigation Johnson et al. [23] studied 18 patients with spastic foot drop. One group of patients received BoNT in addition to physiotherapy and ES. The other (control) group received only physiotherapy. The physiotherapy programme was not standardised and varied according to the patient's treatment goals. The study primary outcome measure was the walking speed over 10 meters. There was a statistically significant increase in the walking speed (of 9\%) in the treatment group. However, the assessments were not blinded and it is not clear whether the observed increase in the walking speed was clinically significant. Furthermore, because of the study design it is impossible to know the separate contribution of each of the three interventions (physiotherapy, BoNT, ES) to the result.

Interestingly, in addition to the obvious limitations of the above studies, their findings have been contradicted by other studies. For example, in a study of 12 patients with spastic foot equinus the combination of BoNT with ES was not found to be superior to BoNT alone in reducing spasticity or improving gait [24].

Similar results were reported by another controlled trial 23 children with ankle plantar flexor spasticity [25]. The patients were randomly allocated to receive BoNT into the gastrocnemius and ES or BoNT and sham ES. Spasticity was assessed with neurophysiological tests (measurement of the compound motor action potential) and clinical methods at baseline and 30 days later. The authors did not find a statistically significant difference between the two groups (Table 1).

\section{Conclusion}

At present there is no robust evidence that the combination of BoNT with physiotherapy, ES or other therapy interventions enhances the beneficial clinical effect of this treatment. The recommendations the British guidelines [6] and the European consensus statement [7] do not take this into account. These recommendations are based mainly on the opinion of experts (level C evidence). They do not fulfil the criteria required for evidence-based practice which needs professional clinical expertise to be integrated with strong evidence from clinically relevant research [26]. It is therefore the author's opinion that the current recommendations are restrictive and, based on the available evidence, it would be difficult to justify denying patients treatment 
Citation: Bakheit AMO (2013) Botulinum Toxin as a Stand-Alone Treatment for Muscle Spasticity: Review of the Evidence. J Neurol Disord 1: 109. doi:10.4172/2329-6895.1000109

Page 3 of 3

\begin{tabular}{|c|c|c|c|c|}
\hline Ref \# & Study description & Sample size & Product and dose & Results \\
\hline [18] & $\begin{array}{l}\text { BoNT+PT versus BoNT alone, } \\
\text { Spasticity due to multiple sclerosis }\end{array}$ & 38 & Botox $100-300$ & $\begin{array}{l}\text { Significant reduction in spasticity as measured with MAS } \\
\text { in the treatment group }(p<0.01)\end{array}$ \\
\hline [19] & BoNT+PT versus PT alone & 36 & NA & $\begin{array}{l}\text { No significant difference between groups as measured } \\
\text { with DTT and GMFM }\end{array}$ \\
\hline [21] & $\begin{array}{l}\text { BoNT+ES versus BoNT alone, lower limb spasticity, } \\
\text { open label design. }\end{array}$ & 10 & Dysport 2000U & $\begin{array}{l}\text { Walking speed increased by } 27 \% \text { in treatment group and } \\
\text { by } 7 \% \text { in control group. }\end{array}$ \\
\hline [22] & BoNT+ES, BoNT alone, placebo+ES, placebo alone. & 6 per group & Dysport $1000 \mathrm{U}$ & $\begin{array}{l}\text { Reduction in MAS more in BoNT=ES and placebo+ES } \\
\text { groups }(p=0.01)\end{array}$ \\
\hline [23] & BoNT+PT+FES versus BoNT+PT, spastic foot drop & 18 & Dysport 600U & Walking speed increased in both groups $(p=0.02)$ \\
\hline [24] & BoNT+PT versus BoNT alone & 12 & $\begin{array}{l}\text { Botox } 7-17.5 \mathrm{U} / \mathrm{kg} \\
\text { body weight }\end{array}$ & $\begin{array}{l}\text { No difference between groups in spasticity or gait } \\
\text { variables. }\end{array}$ \\
\hline [25] & $\begin{array}{l}\text { BoNT+ES vs BoNT+sham ES, children with spastic } \\
\text { diplegia }\end{array}$ & 23 & $\begin{array}{l}\text { Botox } 4-5 \mathrm{U} / \mathrm{kg} \text { body } \\
\text { weight }\end{array}$ & $\begin{array}{l}\text { No difference in neurophysiological (CAMP) or clinical } \\
\text { measures of spasticity }\end{array}$ \\
\hline
\end{tabular}

Key: PT: Physiotherapy; MAS: Modified Ashworth Scale; ES: Electrical stimulation; FES: Functional Electrical Stimulation; DTT: Diffusion Tensor Tractography; GMFM: Gross Motor Function measure; CAMP: Compound Motor Action Potential.

Table 1: The evidence for the enhanced clinical effect of BoNT combination therapy.

with BoNT if other forms of therapy cannot be arranged to coincide with, or shortly follow the BoNT injections.

\section{References}

1. Simpson DM, Alexander DN, O'Brien CF, Tagliati M, Aswad AS, et al. (1996) Botulinum toxin type A in the treatment of upper extremity spasticity: a randomized, double-blind, placebo-controlled trial. Neurology 46: 1306 1310.

2. Bakheit AM, Thilmann AF, Ward AB, Poewe W, Wissel J, et al. (2000) A randomized, double-blind, placebo-controlled, dose-ranging study to compare the efficacy and safety of three doses of botulinum toxin type $A$ (Dysport) with placebo in upper limb spasticity after stroke. Stroke 31: 24022406.

3. Brashear A, Gordon MF, Elovic E, Kassicieh VD, Marciniak C, et al. (2002) Intramuscular injection of botulinum toxin for the treatment of wrist and finger spasticity after a stroke. N Engl J Med 347: 395-400.

4. Bhakta BB, Cozens JA, Bamford JM, Chamberlain MA (1996) Use of botulinum toxin in stroke patients with severe upper limb spasticity. J Neurol Neurosurg Psychiatry 61: 30-35.

5. Bakheit AM, Fedorova NV, Skoromets AA, Timerbaeva SL, Bhakta BB, et al. (2004) The beneficial antispasticity effect of botulinum toxin type $A$ is maintained after repeated treatment cycles. J Neurol Neurosurg Psychiatry 75: 1558-1561.

6. Royal College of Physicians of London, British Society of Rehabilitation Medicine, Chartered Society of Physiotherapy, Association of Chartered Physiotherapists Interested in Neurology (2009). Spasticity in adults: management using botulinum toxin. National guidelines. Royal College of Physicians, London.

7. Ward AB, Aquilar M, De Beyl Z, Gedin S, Kanovsky P, et al. (2004) Use of botulinum toxin type $A$ in management of adult spasticity. A European consensus statement. J Rehabil Med 40: 83-87.

8. Bakheit AM, Zakine B, Maisonobe P, Aymard C, Fhedoroff K, et al. (2010) The profile of patients and current practice of treatment of upper limb muscle spasticity with botulinum toxin type A: an international survey. Int J Rehabil Res 33: 199-204.

9. Shaari CM, Sanders I (1993) Quantifying how location and dose of botulinum toxin injections affect muscle paralysis. Muscle Nerve 16: 964-969.

10. Borodic GE, Ferrante R, Pearce LB, Smith K (1994) Histologic assessment of dose-related diffusion and muscle fiber response after therapeutic botulinum A toxin injections. Mov Disord 9: 31-39.

11. de Paiva A, Meunier FA, Molgó J, Aoki KR, Dolly JO (1999) Functional repair of motor endplates after botulinum neurotoxin type A poisoning: biphasic switch of synaptic activity between nerve sprouts and their parent terminals. Proc Natl Acad Sci U S A 96: 3200-3205.

12. Black JD, Dolly JO (1986) Interaction of 125I-labeled botulinum neurotoxins with nerve terminals. II. Autoradiographic evidence for its uptake into motor nerves by acceptor-mediated endocytosis. J Cell Biol 103: 535-544.

13. Gardiner PF, Michel R, ladeluca G (1984) Previous exercise training influences functional sprouting of rat hindlimb motoneurons in response to partial denervation. Neurosci Lett 45: 123-127.

14. Tam SL, Archibald V, Jassar B, Tyreman N, Gordon T (2001) Increased neuromuscular activity reduces sprouting in partially denervated muscles. J Neurosci 21: 654-667.

15. Kim HS, Hwang JH, Jeong ST, Lee YT, Lee PK, et al. (2003) Effect of muscle activity and botulinum toxin dilution volume on muscle paralysis. Dev Med Child Neurol 45: 200-206.

16. Hughes R, Whaler BC (1962) Influence of nerve-ending activity and of drugs on the rate of paralysis of rat diaphragm preparations by $\mathrm{Cl}$. botulinum type A toxin. J Physiol 160: 221-233.

17. Bandholm T, Jensen BR, Nielsen LM, Rasmussen H, Bencke J, et al. (2012) Neurorehabilitation with versus without resistance training after botulinum toxin treatment in children with cerebral palsy: a randomized pilot study. NeuroRehabilitation 30: 277-286.

18. Giovannelli M, Borriello G, Castri P, Prosperini L, Pozzilli C (2007) Early physiotherapy after injection of botulinum toxin increases the beneficial effects on spasticity in patients with multiple sclerosis. Clin Rehabil 21: 331337.

19. Chaturvedi SK, Rai Y, Chourasia A, Goel P, Paliwal VK, et al. (2012) Comparative assessment of therapeutic response to physiotherapy with or without botulinum toxin injection using diffusion tensor tractography and clinical scores in term diplegic cerebral palsy children. Brain Dev S0387 7604: 00270-0027.

20. Thorley M, Donaghey S, Edwards P, Copeland L, Kentish M, et al. (2012) Evaluation of the effects of botulinum toxin $A$ injections when used to improve ease of care and comfort in children with cerebral palsy whom are nonambulant: a double blind randomized controlled trial. BMC Pediatr 12: 120.

21. Hesse S, Jahnke MT, Luecke D, Mauritz KH (1995) Short-term electrical stimulation enhances the effectiveness of Botulinum toxin in the treatment of lower limb spasticity in hemiparetic patients. Neurosci Lett 201: 37-40.

22. Hesse S, Reiter F, Konrad M, Jahnke MT (1998) Botulinum toxin type A and short-term electrical stimulation in the treatment of upper limb flexor spasticity after stroke: a randomized, double-blind, placebo-controlled trial. Clin Rehabil 12: 381-388.

23. Johnson CA, Burridge JH, Strike PW, Wood DE, Swain ID (2004) The effect of combined use of botulinum toxin type $A$ and functional electric stimulation in the treatment of spastic drop foot after stroke: a preliminary investigation. Arch Phys Med Rehabil 85: 902-909.

24. Detrembleur C, Lejeune TM, Renders A, Van Den Bergh PY (2002) Botulinum toxin and short-term electrical stimulation in the treatment of equinus in cerebral palsy. Mov Disord 17: 162-169.

25. Rha DW, Yang EJ, Chung HI, Kim HB, Park Cl, et al. (2008) Is electrical stimulation beneficial for improving the paralytic effect of botulinum toxin type $\mathrm{A}$ in children with spastic diplegic cerebral palsy? Yonsei Med $\mathrm{J} 49$ : 545-552.

26. Sackett DL, Rosenberg WM, Gray JA, Haynes RB, Richardson WS (1996) Evidence based medicine: what it is and what it isn't. BMJ 312: 71-72. 